\title{
Consumer Choice Behavior On The Web: The Effects Of Product Attributes On Willingness To Purchase
}

Yooncheong Cho, (E-mail: ycho@hpu.edu), Hawaii Pacific University Joseph Ha, (E-mail: jha@hpu.edu), Hawaii Pacific University

\begin{abstract}
This study investigates how consumers' choice behavior in the electronic marketplace depends on their ability to judge product attributes and how willingness to purchase products is affected by the different attributes of the products. This study applied von Neumann-Morgenstern utility theory to explain how consumers combine perceptions of product attributes into preferences under uncertain situations in the electronic marketplace and employed The Dot-Com Retail Continuum, proposed by Figueiredo (2000), to classify the products online. Major findings suggest that a consumer's purchase decision in the electronic marketplace is affected by that consumers' ability to assess the product attributes and also propose competitive strategies on various product categories to the dot-com retailers.
\end{abstract}

\section{Introduction}

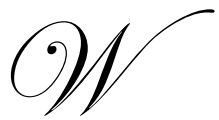

hat products are consumers willing to purchase on the Web? How does consumers' choice behavior differ in the online context from in the traditional marketplace? Due to the computermediated shopping environment (Hoffman and Novak 1996), consumers, in the online environment, are not able to determine the attributes of products easily and their selection of and satisfaction with those products differ greatly based on different product categories. This study also posits that consumers' willingness to purchase a product and their e-satisfaction on the Web rely on product categories, which have different attributes. The present study extends the prior research by Figueiredo (2000) and Cho et al. (2003), which posits that i) all products are not equal on the Web, because products possess different attributes and different levels of the same products and ii) those attributes are not easily delivered to the individual consumer in the online context.

Based on the consideration above, the purpose of this study is to investigate i) what factors affect consumer's willingness to purchase on the Web; ii) how consumer's choice behavior on the Web differ depending on the product categories; iii) how different levels (i.e., different purchasing options, such as 5\% discount, $1 \%$ discount, etc.) affect consumer's choice behavior on the Web; and iv) how consumers' choice behavior on different product attributes affects their satisfaction. This study applied von Neumann-Morgenstern utility theory to explain how consumers combine perceptions of product attitudes into preferences under uncertain situations on the Web (Hauser and Urban 1979). The Dot-Com Retail Continuum, proposed by Figueiredo (2000) was employed in this study to classify the products online.

\section{Conceptual Framework}

\section{Consumer Choice Behavior On the Web}

How do online customers evaluate a product's attributes in cyberspace? We address this question by exploring different consumer choice behavior in the online context from offline environment. Few studies have explored consumer choice behavior in the online environment, especially with product attributes, while product attributes have played a pivotal role in influencing consumer choice behavior on the Web. Various researchers have 
discussed consumer choice behavior in the traditional market environment. Many researchers addressed the level of ambiguity in the choice context, which often determines the degree of uncertainty with which preferences are held (Muthkrishnan and Kardes 2001). In the online environment, ambiguity and uncertainty are caused because of the computer-mediated environment, as consumers are not able to physically see/touch/smell/hear the products. Since all products are not equal on the Web, due to the inherent characteristics of online shopping (Degeratu et al. 2000; Figueiredo 2000; Kiely 1996; Cho et al. 2003), consumers cannot easily assess product quality in the computermediated shopping environment, while the majority of them rely on their prior beliefs and preferences about alternatives (Figueiredo 2000; Hauser and Wernerfelt 1990; Ratchford 1982; Roberts and Lattin 1991; Simonson, Huber, and Payne 1988). Consumers' purchase decisions also often rely on factors, such as prior experiences, perceived quality, brand name, price, and their ability to judge the product. Alba et al. (1997) particularly addressed that consumers are more likely dependent on their prior shopping experiences in the online shopping environment and also in the case of interactive home shopping. Direct marketing shopping environments, such as online, home, and catalog shopping have similarities due to the fact that consumers' cannot physically touch/smell/see/hear the product before they make a purchase decision. Therefore, in order to help decision making, consumers often rely on memory for the generation of alternatives for consideration (Alba et al. 2001; Alba and Chattopadhyay 1985; Hutchinson, Raman, and Mantrala 1994). Lynch et al. (1988) also stressed that in many choices, in the real world, the consumer must remember some or all of the alternatives.

This study applied Von Neumann-Morgenstern utility theory to explain the application of utilities to the method of decision analysis (Hauser and Urban 1979). According to Hutchinson (1986), preferences for attributes are central to several value maximization models of consumer choice, such as various multiattribute utility models. Utilities have been frequently applied for several discrete attribute levels. Marginal utility has been known as an amount of benefit derived from consuming one additional unit of a product or service. Utilities also can be transformed using statistical methods like ordinary least squares regression, weighted least squares regression, and logit analysis. This study follows the function below (1), to measure utilities by fitting a multiple regression model for the individual (Scott and Wright 1976).

$$
U\left(x_{i}\right)=b_{o}+\sum_{j=1} b_{j} x_{i j}
$$

where

$U\left(x_{i}\right)$ : A numerical judgment about the product's overall utility.

$x_{i j}$ : Numerical scale vales describing the product on the $j$ th dimension

$b_{j}$ : Regression coefficients the relative stress the person gave to the $j$ th dimension across judgments.

\section{Product Classification: The Effects of Attributes}

Various researchers (Cho et al. 2003; Figueiredo 2000) have addressed how purchasing behavior in the online context differs from the traditional market place based on what types of products/service customers have in mind. In traditional marketing, researchers (Murphy and Enis 1986) suggested that products are classified in terms of buyer's evaluation of the price, namely, convenience, preference, shopping, and specialty goods. Other dimensions, proposed by marketers (Murphy and Enis 1986) are risk and effort. Risk (Murphy and Enis 1986) in the literature is defined as the buyer's subjective feeling about the monetary and non-monetary price of the product, while effort is defined as the objective amount of money and time it takes to purchase a product (see also cho et al. 2003). According to these dimensions, convenience products (e.g., fresh produce, grocery staples, etc.) are defined as lowest in terms of both effort and risk (Murphy and Enis 1986); preference products (e.g., beer, soft drinks, etc.) are slightly higher in the effort dimension and much higher in risk; shopping products (e.g., automobiles, clothing, furniture, etc.) include increased levels of risk and also are perceived by consumers as high involvement products; and specialty products (e.g., vintage wines, expensive cars, etc.) are defined to be highest in both risk and effort. 
However, different dimensions for product classification in the online context are suggested by researchers. According to Figueiredo (2000), products can be classified on the Web based on how easily consumers can evaluate the product quality in the online context. Researchers noted that product attributes are an important key for consumers on the Web to judge product quality and make a purchase decision (Degeratu et al. 2000; Figueiredo 2000; Kiely 1996). Therefore, the literature assumes that the customer's ability to evaluate product quality on the Web differs according to product attributes (Figueiredo 2000; Kiely 1996; Cho et al. 2003). Risk and effort could be also major concerns for product classification in the online environment. However, on the Web, perceived risk is generated from buyer's subjective feeling due to the perceived uncertainty about the product quality, as s/he cannot physically see the product. Perceived effort in the online context relies on consumers' ability to find information on the Web and to assess product quality. An early study of product classification in the online context is by Kiely (1996), suggesting a dimension called the degree of requirements of consumer's physical presence. Kiely (1996) noted that interactive home shopping depends on the requirements of the consumer's physical presence (Cho et al. 2003). Shoppers at Home Depot, for example, typically inspect the size, specifications, or colors of the tools, gadgets, and other building materials they are planning to purchase, and often seek advice from the retailer's sales associates (Kiely 1996). Thus, if retailers are to succeed in interactive home shopping, they will need to develop a much more sophisticated understanding of how to create and deliver detailed product information to their customers.

Another study of product classification is by Degeratu et al. (2000) and Figueiredo (2000). Degeratu et al. (2000) suggested two categories, called Sensory vs. Non-Sensory products. This category was suggested because online transactions differ from traditional exchanges in terms of a product's sensory attributes such as touch, smell, or sound. Sensory products were defined as those that have attributes that can be conveyed through our senses, particularly touch, smell, or sound, while non-sensory products were defined as products with attributes that can be conveyed reasonably well in words (Degeratu et al. 2000). The study by Cho et al. (2002) found that online customers' complaints are greater with sensory products than with non-sensory products, particularly when customers are dissatisfied with the presentation of the information provided for the sensory product compared to information for the non-sensory product. A recent study by Cho et al. (2003) shows that sensory and non-sensory product classification affect the degree of dissatisfaction involving factors, such as cost, time effort, and ego involvement.

Studies by Kiely (1996) and Cho et al. (2002) both suggested that products with a higher physical presence (i.e., customers must see, touch, or smell the product) should provide as much sophisticated information as possible (Cho et al. 2003). In other words, on the Web, due to the inherent limitation in delivering sensory information, it is hard to make sound decisions for sensory products regardless of the time and effort spent on the information search (Cho et al. 2003). However, in the in-store environment, there is a good chance that decision quality increases if customers spend more time and effort in the information search for sensory products. It suggests that on the Web, tools for more detailed and sophisticated information will be needed for products that have such attributes.

For the classification of the product category on the Web, Figueiredo (2000) addressed whether quality is easy or difficult to judge in products on the Web. Products on the Web are unequal due to the inability to deliver actual services or adequately detail the specific nature of many products. Therefore, a product's attributes are not evaluated equally by customers on the Web (Figueiredo 2000). Four product categories on the Web by Figueiredo (2000) include commodity products (e.g., oil, paper clips), quasi-commodity products (e.g., books, CDs, videos, or toys), look-and-feel goods (e.g., suits, furniture, model homes, etc.), and look-and-feel goods with variable quality (e.g., arts, produce, etc). According to the product continuum on the Web by Figueiredo (2000), product category moves from commodity product to look-and-feel goods with variable quality, as a product's attributes are not easily evaluated by customers.

Previous studies (Figueiredo 2000) suggested market strategies and tactics for maximizing dot-come opportunity based product categories. For example, businesses dealing with commodity products should focus on low cost strategy utilizing a low-cost production technology, also taking advantage of the economies of scale (Figueiredo 2000). For quasi-commodity products, Figueiredo (2000) proposed that dot-com businesses should use information technology to differentiate web service. For look-and-feel products, dot-coms should establish the equivalent of store brands. The role of brand name for look-and-feel goods is important, when consumers make a 


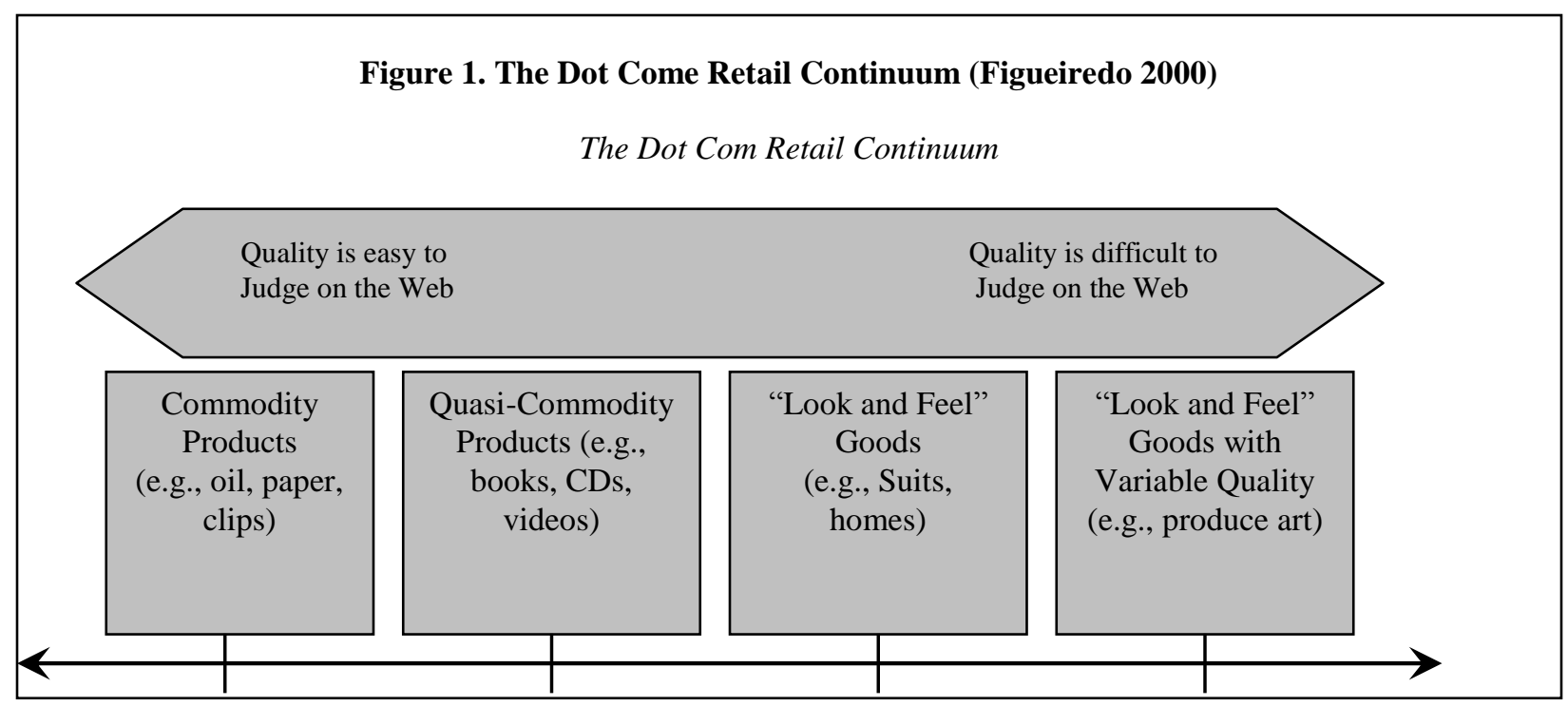

purchase decision for such products due to the inherent characteristics of the computer-mediated shopping environment. Brand names could be an important cue for not only look-and-feel goods but also look-and-feel with variable quality. Figueiredo (2000) suggested dot-coms keep abreast of and use advanced Web-cam technology. Prior studies also suggested that brand name, price, and other search attributes are factors that affect consumer choice behavior (Degeratu, Rangaswamy, and Wu 1999).

Figure 2. The Proposed Model of The Present Study

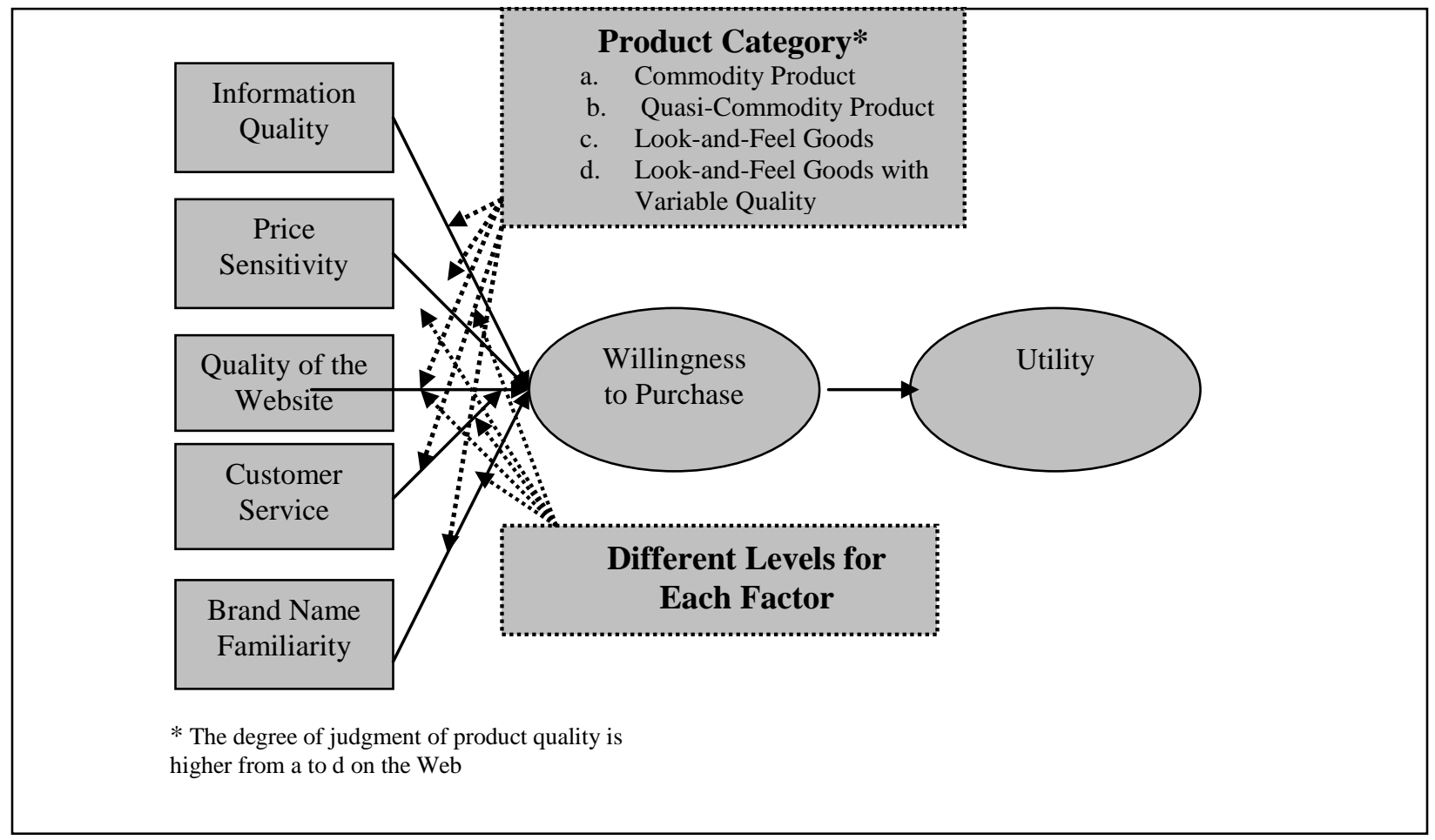


Based on the literature reviews, this study proposes that five factors such as information quality, price, graphical presentation, customer service, and brand name affect online consumers' willingness to purchase (see figure 2).

This study considers different levels for each factor to investigate how online consumers' willingness to purchase varies based on different levels and also le. Different levels proposed in this study are listed below in table 1.

Table 1. Different Levels for Each Factor

\begin{tabular}{|l|l|}
\hline \multicolumn{1}{|c|}{ Factors } & Levels \\
\hline Information Quality & a. Detail \\
& b. Average quality \\
& c. Poor \\
\hline Price Sensitivity & a. $10 \%$ lower than physical retailer \\
& b. 5\% lower than physical retailer \\
& c. 5\% lower than other online retailer \\
& d. Almost same as the price from physical retailer \\
& e. 5\% higher than physical retailer \\
\hline Quality of the Website & a. Graphical presentation is quite advanced. \\
& b. Graphical presentation has average quality. \\
& c. Graphical presentation is poor. \\
\hline Customer Service & a. High quality. \\
& b. Average quality. \\
& c. Poor quality. \\
\hline Brand Name Familiarity & a. Quite familiar. \\
& b. Heard about it, but not so familiar. \\
& c. Not familiar at all. \\
\hline
\end{tabular}

\section{Information Quality Factor}

The information factor has been an important cue for decision-making. Degeratu, Rangaswamy, and Wu pointed out that information availability affects consumers' decision making and it differs in the online from offline environments. Dick et al. (1990) also addressed that consumers focus on relevant attributes that are available and are diagnostic when they search for information in the online context. While information availability has been considered to investigate consumer behavior on the Web, this study focuses on the quality of information. The current web sites provide a certain degree of information and also most online users are able to search for a certain amount of information. A more important factor than information availability that affects consumer's decisionmaking on the Web is how the dot-com business provides a higher quality of information. Cho and Ha (2003) posit that the quality of information content provided by websites often reduces users' search efforts and agitates behavioral intention to use. This study hypothesizes that online consumers' willingness to purchase increases as their perceived information quality increases.

Hypothesis 1: In the online environment, as consumers' perceived information quality increases, their willingness to purchase will increase.

Hypothesis 1a: This impact will be different based on product categories on the Web.

\section{Price Sensitivity Factor}

Various researchers have stressed the role of price on consumer choice behavior and buying decisions (Krishnamurthi and Raj 1988). According to Lichtenstein, Ridgway, and Netermeyer (1993), price is unquestionably one of the most important marketplace cues. The role of price also becomes an important factor in the online environment. It has been argued that online consumers are more sensitive about price as consumers are able to easily compare prices online. In a particular, online companies that provide price comparisons, such as cnet.com or epinions.com, enhance price sensitivity on the Web. Online consumers' expectations for lower prices could be even 
higher than in the offline environment as e-businesses often provide lower price reducing costs and manage efficient distribution systems. When online stores maintain an efficient distribution system, they are better able to reduce costs, yet they don't always offer lower prices than physical stores. Effective online distribution systems such as just-in-time inventory, EDI (Electronic Data Interchange), and supply chain management, play a role in reducing costs. Movie-related website users save money and time by purchasing by purchasing tickets online. Hanson (2000) posits that the Internet will raise or lower price sensitivity among customers. The authors of this study posit that price sensitivity tends to increase in the online environment due to the availability of price comparisons on the Web. Based on this consideration, this study also suggests that e-businesses should employ better pricing strategies to meet consumers' expectations. Figueiredo (2000) suggested different pricing strategies for different product categories. Particularly, creative pricing strategies have been suggested for "look-and-feel goods", specifically for time- preference based pricing (Figueiredo 2000). This study hypothesizes that online consumers price sensitivity affects their willingness to purchase products.

Hypothesis 2: As consumers perceive lower the price in the online environment than in the offline environment, consumers' willingness to purchase.

Hypothesis 2a: This impact will be different based on product categories on the Web.

\section{Website Quality}

Web interface design and technology are essential for all electronic businesses.

Sensory products do not convey all the attributes of products on the Web. According to Figueiredo (2000), customers need to see and touch products such as produce and art despite recognizing the brand and knowing the product. Therefore, customers are not likely to purchase sensory products with variable quality online, because their satisfaction after the purchase might not reach prior expectations. Thus, in an effort to fulfill customer expectations for those products, e-businesses sell sensory products only by providing customized technologies, such as pictures of the products, enlargements of the products, and size charts, etc. Frontier websites, such as www.landsend.com, use advanced Web features such as a three-dimensional mirror images to reduce the uncertainty of the clothes they sell on the Web. Based on previous work, this study used the product classification by Degeratu et al. (2000) and Kiely (1996), sensory vs. non-sensory products.

The study assumes that customers might be reluctant to purchase products with sensory attributes on the Web because they cannot measure those attributes. As Cho et al. (2003) found, customers' dissatisfaction with sensory products on the Web might be higher than their dissatisfaction with such products in the physical market place. Figueiredo (2000) suggested that dot-coms dealing with "look-and-feel goods" and "look-and-feel" with variable quality should excel customer interface using advanced technology. Thus, this study hypothesizes that the effect of graphical presentation using technology is greater with "look-and-feel goods" and "look-and-feel" with variable quality products than with "commodity product" or "quasi- commodity products."

Hypothesis 3: As consumers perceive that one website's graphical presentation is better than its competitor's, their willingness to purchase a product increases on the Web.

Hypothesis 3a: This impact will be different based on product categories on the Web.

\section{Customer Service Factor}

Prior researchers have noted that customer service is a major key to success for e-businesses. In the computer-mediated environment, customers need additional information, which is often obtained from a salesperson in the offline shopping environment. Therefore, customer service is the online equivalent of a sales-person. Most recently, many online firms have begun offering "instant chatting services" in order to minimize queuing time. In order to obtain a competitive advantage, various studies (Figueiredo 2000; Cho et al. 2003) suggested that online firms should excel at customer service with both interactive and phone customer support. The importance of technology to enhance service quality has been addressed by researchers. For example, Bitner et al. (2000) found that technology is incorporated into the service-marketing triangle, both supporting and facilitating service delivery. 
A study by Bitner et al. (2000) also discussed the role of technology in implementing effective service recoveries and encouraging customer complaining (see also Brown 1997). Most online firms manage Web-based customer service centers to deal with customer comments and complaints, utilizing sophisticated technology (Cho et al. 2002). Moreover, it is essential for online businesses selling "look-and-feel goods" and "look-and-feel" with variable quality products to offer superior customer service (Cho et al. 2003), in order to minimize uncertainty about their products.

Hypothesis 4: As consumers perceive better customer service, their willingness to purchase a product increases on the Web.

Hypothesis 4a: This impact will be different based on product categories on the Web.

\section{Brand Name factor}

The role of brand recognition has been frequently addressed in previous studies. Dick et al. (1990) pointed out that brand value inferences depend on the accessibility of information. In traditional marketing, brand names serve a variety of purposes for consumers and advertisers (Meyers-Levy 1989). Brand awareness plays a crucial role on consumer decision making for many reasons (Keller 1993). It is important that consumers think of the brand when they think about the product category and also raising brand awareness increases the likelihood of that brand being a member of the consideration set (Baker and Nedungadi 1986). Various researchers (e.g., Levy 1989) have proven that firms with extremely memorable brand names often regard the names as their most valuable asset because these labels provide immediate recognition, and often, acceptance of new products that may be introduced under the brand name.

This study points out that brand names are also significant in the online environment. Consumers log on to certain website based on their recognition of the brand names. The role of the URL (Uniform Resource Locator), which represents the online business, is also important as online consumers recall e-commerce sites depending on how memorable the URL is.

Therefore, brand names could help consumers make purchase decisions in the computer - mediated environment as those enable highly reliable inferences about consumption benefits after one purchase and use (Alba et al. 1997). This study hypothesizes that brand name familiarity affects consumer willingness to purchase products in the electronic marketplace.

Hypothesis 5: As consumers' familiarity with a brand name increases, their willingness to purchase a product increases on the Web.

Hypothesis 5a: This impact will be different based on product categories on the Web.

\section{Methodology}

This study performed the survey using current Internet consumers. Approximately three hundred subjects randomly selected in the U.S. participated in this survey Four products such as paper, books, apparel, and produce were selected from each of the four product categories in The Dot-Com Retail Continuum (Figueiredo 2000): Commodity products, Quasi-commodity products, "Look and Feel Goods," and "Look and Feel Goods with Variable Quality." The study used the rating scales (1-7) to obtain consumers' perceptions toward product attributes.

This study employed principal components analysis as an extraction method, while varimax with Kaiser normalization was used as a rotation method. Varimax rotation method was applied because the correlations between factors are low with the oblique rotation method. Factor analysis was conducted to select the best set of questionnaire items for variables. Factors such as information quality, price, Website quality, customer service, and brand name awareness were used to predict willingness to purchase.

This study analyzed the data in two ways. First, this study ran the regression analysis using factor scores, obtained from the factor analysis. Second, this study ran the regression analysis considering dummy variables for different levels, proposed in table 1 . Three levels were used for factors, while five levels were used for the price 
factor. Therefore, two dummy variables were used for four factors (information, quality of the website, customer service, and brand name), and four dummy variables were used for the price factor. One of the levels was used as a base. For the dependent variable, this study used willingness to purchase to see the changes of degree based on different levels of the factors, affect choice behavior and also different product categories. In addition, preference regression analysis (Carroll 1972) was used to fit a utility function to stated preferences and also to investigate how a consumer's choice behavior on the Web is not equal based on individual perceptions toward the uncertainty when certain product attributes are not judged on the Web.

\section{Results}

Major findings suggest that a consumer's purchase decision on the Web is affected by that consumer's ability to assess product attributes due to the limitation of electronic commerce. The finding of this study also proposes competitive strategies on various product categories to dot-com retailers by confirming Figueiredo (2000)'s work. Further, the present study contributes to theory development by applying concepts from traditional marketing to the electronic commerce context.

First, this study employed principal components analysis to find the five factors that affect utilities. Orthogonal varimax rotation method instead of the oblique rotation was applied because the correlations between factors are low when oblique method is applied in this analysis. The result of the factor analysis was converged in five constructs after the second-order results of the factor analysis. Table 2 presents the final result of the factor analysis with varimax rotation. The final result was chosen as the best sets to describe the factors for a customer's willingness to purchase. Based on the Kaiser criterion, eigen values greater than 1 were selected. Among the 20 indicators, 12 items (three items from information quality: two from price; three from brand name; two from customer service; and two from website quality) were selected as a result of the factor analysis. Thus, the second order factor analysis was based on the items remaining from the previous result.

Table 2 Component Matrix (Rotated)

\begin{tabular}{|l|c|c|c|c|c|}
\hline \multirow{2}{*}{ Items } & \multicolumn{5}{|c|}{ Component } \\
\cline { 2 - 6 } & 1 & 2 & 3 & 4 & 5 \\
\hline Information Quality 4 & .899 & & & & \\
Information Quality 2 & .782 & & & & \\
Information Quality 3 & .777 & & & & \\
Price 1 & & .969 & & & \\
Price 3 & & .951 & & & \\
Brand Name 5 & & & .857 & & \\
Brand Name 4 & & .818 & & \\
Brand Name 3 & & .698 & .918 & \\
Customer Service 1 & & & & .858 & \\
Customer Service 2 & & & & .707 & \\
Customer Service 4 & & & & & .864 \\
Web Site Quality 1 & & & & & .718 \\
Web Site Quality 3 & 2.980 & 1.987 & 1.685 & 1.344 & 1.191 \\
\hline Eigen Value & & &
\end{tabular}

Table 3 displays the correlation matrix among the remaining 12 items. Similar to the correlation matrix result for the online case, all the correlations between the items, which represent the same variable, showed significant relationships, while the correlations among the different variables had low multicollinearity. Pearson correlation coefficients were high among the items, but low between the items. This indicates an adequate level of discriminant validity. Table 4 shows the regression analysis results using the factor scores. The results show all factors positively affect consumers' willingness to purchase. 
Table 3 Correlation Matrix Among Indicators

\begin{tabular}{|c|c|c|c|c|c|c|c|c|c|c|c|c|}
\hline & INFO4 & INFO2 & INFO3 & PRC1 & PRC3 & BN5 & BN4 & BN3 & CS1 & CS2 & WSQ1 & WSQ3 \\
\hline INFO4 & 1.000 & & & & & & & & & & & \\
\hline INFO2 & .810 & 1.000 & & & & & & & & & & \\
\hline INFO3 & .558 & .643 & 1.000 & & & & & & & & & \\
\hline PRC1 & .156 & .227 & .155 & 1.000 & & & & & & & & \\
\hline PRC3 & .020 & .096 & .150 & .468 & 1.000 & & & & & & & \\
\hline BN5 & .164 & .143 & .066 & .185 & .147 & 1.000 & & & & & & \\
\hline BN4 & -.133 & -.116 & .110 & .019 & .302 & .411 & 1.000 & & & & & \\
\hline BN3 & .028 & .050 & .110 & -.005 & .225 & .753 & .590 & 1.000 & & & & \\
\hline CS1 & .192 & .231 & .244 & .084 & .090 & .193 & .165 & .046 & 1.000 & & & \\
\hline CS2 & .138 & .148 & .269 & .119 & .194 & .235 & .137 & .005 & .722 & 1.000 & & \\
\hline WSQ1 & .047 & .063 & -.026 & .069 & -.013 & .217 & .036 & -.036 & .189 & .276 & 1.000 & \\
\hline WSQ3 & .119 & .146 & .258 & .125 & .178 & .219 & .106 & .063 & .235 & .254 & .656 & 1.000 \\
\hline
\end{tabular}

- $\quad$ INFO = Information Quality; PRC = Price; BN = Brand Name;

- $\quad \mathrm{CS}=$ Customer Service; and WSQ = Web Site Quality.

Table 4 The Effects of Factors on the Willingness to Purchase

\begin{tabular}{|l|c|}
\hline \multirow{2}{*}{ Variable } & Standard Coefficient $(\boldsymbol{t}$-value (Sig)) \\
\cline { 2 - 2 } & Willingness to Purchase \\
\hline Information Quality & $.314\left(4.764^{* *}\right)$ \\
\hline Price Sensitivity & $.281\left(3.911^{* *}\right)$ \\
\hline Website Quality & $.353\left(4.472^{* *}\right)$ \\
\hline Customer Service & $.391\left(4.685^{* *}\right)$ \\
\hline Brand Name Familiarity & $.321\left(4.245^{* *}\right)$ \\
\hline \multirow{2}{*}{ Significant at 0.01 level (2-tailed) }
\end{tabular}

Table 5 shows the results of Ordinary Least Squares (OLS) regression analyses. The table displays the results for four-product categories: commodity product, quasi-commodity product, look-and-feel goods, and lookand-feel goods with variable quality. A linear model was used for the analysis of OLS regression.

Table 5 The Impact of Different Levels on Consumers' Willingness to Purchase on the Web

\begin{tabular}{|c|c|c|c|c|}
\hline \multirow[b]{2}{*}{ Variables* } & \multicolumn{4}{|c|}{ Standardized Coefficients } \\
\hline & Commodity Product & $\begin{array}{c}\text { Quasi-Commodity } \\
\text { Product }\end{array}$ & Look-and Feel Goods & $\begin{array}{c}\text { Look-and-Feel with } \\
\text { Variable Quality }\end{array}$ \\
\hline INFO-Dummy 1 & $.219(3.551 * *)$ & $.301(4.022 * *)$ & $.314(4.451 * *)$ & $.337\left(4.443^{* *}\right)$ \\
\hline INFO-Dummy 2 & $.138(2.367 * *)$ & $.206(2.875 * *)$ & $.236(3.411 * *)$ & $.299(3.203 * *)$ \\
\hline PRC-Dummy 1 & $.441(5.519 * *)$ & $.462(5.611 * *)$ & $.488(5.788 * *)$ & $.493(5.911 * *)$ \\
\hline PRC-Dummy 2 & $.342(4.650 * *)$ & $.357(4.887 * *)$ & $.391(4.980 * *)$ & $.397(4.999 * *)$ \\
\hline PRC-Dummy 3 & $.321(4.517 * *)$ & $.371(4.901 * *)$ & $.388(4.975 * *)$ & $.375(4.815 * *)$ \\
\hline PRC-Dummy 4 & $.011(1.011)$ & $.009(1.101)$ & $.093(1.091)$ & $.013(1.201)$ \\
\hline BN-Dummy 1 & $.321(4.221 * *)$ & $.348(4.373 * *)$ & $.391(4.481 * *)$ & $.399(4.588 * *)$ \\
\hline BN-Dummy 2 & $.200(3.09 * *)$ & $.222(3.390 * *)$ & $.211(3.212 * *)$ & $.213(3.301 * *)$ \\
\hline CS-Dummy 1 & $.339(4.911 * *)$ & $.339(4.911 * *)$ & $.339(4.911 * *)$ & $.339(4.911 * *)$ \\
\hline CS-Dummy 2 & $.209(3.192 * *)$ & $.209(3.192 * *)$ & $.209(3.192 * *)$ & $.209(3.192 * *)$ \\
\hline WSQ-Dummy 1 & $.344(4.652 * *)$ & $.376(4.772 * *)$ & $.389(4.998 * *)$ & $.390(4.999 * *)$ \\
\hline WSQ-Dummy 2 & $.224(3.144 * *)$ & $.245(3.322 * *)$ & $.247(3.324 * *)$ & $.256(3.433 * *)$ \\
\hline R-Square & .697 & & & \\
\hline
\end{tabular}

** Significant at 0.01 level (2-tailed).

* Bases, used for dummy variables:

- Information Quality - Information quality is poor.

- $\quad$ Price $-5 \%$ higher than physical retailer.

- Website Quality - Graphical presentation is poor.

- Customer Service - Customer Service, offered by online business is poor.

- $\quad$ Brand Name - Brand Name is not familiar at all. 
This study compared the standardized coefficient found for different product categories to examine how the factors affect consumer choice behavior on willingness to purchase on the Web. The results of comparison analysis found some consistent results with the previous work proposed by Figueiredo (2000). For example, the results indicate that a familiarity with the brand name is more important with look-and-feel goods and look-and-feel goods with variable quality than commodity and quasi-commodity products. Particularly, consumers' price sensitivity was higher with look-and-feel goods and look-and-feel goods with variable quality than commodity and quasicommodity products when the same amount was offered compared to the online than non-online retailer. Consumers are more sensitive to discounted price with look-and-feel goods and look-and-feel goods with variable quality than commodity and quasi-commodity products. Consumers' subjective requirement of advanced customer service is higher with look-and-feel goods and look-and-feel goods with variable quality than with commodity and quasicommodity products. The perceived need for quality of website is more important with look-and-feel goods and look-and-feel goods with variable quality than with commodity and quasi-commodity products.

As table 6 shows, this study also found the impacts of willingness to purchase on utility. The study found that willingness to purchase significantly affects utility, which is equivalent to consumer satisfaction.

Table 6 The Effects of Willingness to Purchase on Utility

\begin{tabular}{|l|c|c|}
\hline Variable & Standard Coefficient* & $\boldsymbol{t}$-value (Sig) \\
\hline Willingness to purchase & .354 & $4.651^{* *}$ \\
\hline
\end{tabular}

** Significant at 0.01 level (2-tailed).

\section{Discussion and Conclusion}

E-businesses are encountered in a computer-mediated environment, so customers have not been able to try, see, or touch the product before it is delivered, unless they are already familiar with them. Therefore, customers' buying behavior in the online shopping environment has been significantly affected by the product categories. This study investigates how factors affect consumer's willingness to purchase on the Web; how consumer's choice behavior on the Web differ depending on the product categories; and how different levels affect consumer's choice behavior on the Web. This study applied von Neumann-Morgenstern utility theory to explain how consumers combine perceptions of product attitudes into preferences under uncertain situations on the Web (Hauser and Urban 1979). The Dot-Com Retail Continuum, proposed by Figueiredo (2000) was employed in this study to classify the products online.

Major findings suggest that a consumer's purchase decision on the Web is affected by that consumer's ability to assess the product attributes due to the limitation of the electronic commerce. The finding of this study also proposes competitive strategies on various product categories to the dot-com retailers by confirming Figueiredo (2000)'s work. Further, the present study contributes to theory development by applying the concepts from traditional marketing to the electronic commerce context. The results of comparison analysis found some consistent results with the previous work, proposed by Figueiredo (2000). For example, the results indicate that online consumers are slightly more sensitive to price when it is lower at a physical retailer than an online retailer. Particularly, consumers' price sensitivity was higher with look-and-feel goods and look-and-feel goods with variable quality than commodity and quasi-commodity products when the same amount was offered compared to the online than other online retailer. Consumers are more sensitive to a discounted price with look-and-feel goods and lookand-feel goods with variable quality than commodity and quasi-commodity products. Consumers' subjective requirement of advanced customer service is higher with look-and-feel goods and look-and-feel goods with variable quality than commodity and quasi-commodity products. The perceived need for quality of website is more important with look-and-feel goods and look-and-feel goods with variable quality than with commodity and quasi-commodity products. 
The study has some limitations. Although this study uses multivariate statistics, such as factor and regression analysis and ANOCOVA, the study didn't measure cause and effect relationship using a program, such as LISREL. The authors will consider this issue on our future research. A framework to classify product categories will be also developed and different product examples for each product category should be considered in our future research. Further, a greater number of subjects will be considered in our further study.

\section{References}

1. Alba, Joseph W. and Chattopadhyay, Amitava (1985), "Effects of Context and Part-Category Cues on Recall of Competing Brands," Journal of Marketing Research, 22, August, pp. 340-49.

2. Alba, Joseph W., John Lynch, Barton Weitz, Chris Janiszewski, Richard Lutz, and Stacy Wood (1997), "Interactive Home Shopping: Consumer, Retailer, and Manufacturer Incentives to Participate in Electronic Marketplaces," Journal of Marketing, (July) 61, 38-53.

3. Baker, W. J. and Nedungadi, P. (1986), "Brand Familiarity and Advertising: Effects on the Evoked Set and Brand Preferences," Advanced in Consumer Research, Vol. 13, Richard J. Lutz ed. Provo, UT: Association for Consumer Research.

4. Bitner, M. J., Brown, Stephen W., and Meuter, Matthew L. (2000), "Technology Infusion in Service Encounters," Journal of the Academy of Marketing Science, (Winter), 28, 1, 138-149.

5. Brown, Stephen W. (1997), "Service Recovery through IT," Marketing Management, Fall.

6. Carroll, J. Douglas (1972), "Individual Differences and Multi-dimensional scaling," in Multidimensional Scaling: Theory and Application in the Behavioral Sciences, eds. R. N. Shepard, A. K. Romney, and S. Nerlove, New York: Seminar Press, Inc., 1.

7. Cho, Y., Im, Il, Fjermestad, J. \& Hiltz, S. (2003), "The Impact of Product Category on Customer Dissatisfaction in Cyberspace," A paper has been accepted in a Special Section on Electronic Customer Relationship Management in the Business Process Management Journal, Winter.

8. Cho, Y. and Ha, J. (2003), "Users' Attitudes Towards Movie-Related Websites and E-Satisfaction," Advertising and Consumer Psychology Conference, Seoul, Korea.

9. Cho, Yooncheong, Im, Il, Hiltz, S. Roxanne, and Fjermestad, Jerry (2002), "An Analysis of Online Customer Complaints: Implications for Web Complaint Management," Proceedings of the $35^{\text {th }}$ Annual Hawaii International Conference on System Sciences, January.

10. Degeratu, Alexandru M., Rangaswamy, Arvind, and Wu, Jianan (2001), "Consumer Choice Behavior in Online and Traditional Supermarkets: The Effects of Brand Name, Price, and Other Search Attributes," International Journal of Research in Marketing, Vol. 17, No. 1, pp.55-78.

11. Dick, Alan, Chakravarti, Dipankar, and Biehal, Gabriel (1990), "Memory-Based Infereneces During Consumer Choice," Journal of Consumer Behavior, Vol. 17, June, pp.82-93.

12. Figueiredo, John M. de (2000), "Finding Sustainable Profitability in Electronic Commerce," Sloan Management Review, summer.

13. Hanson, Ward (2000), Principles of Internet Marketing, South-Western College Publishing.

14. Hauser, John R. and Urban, Glen L. (1979), "Assessment of Attribute Importances and Consumer Utility Functions: von Neumann-Morgenstern Theory Applied to Consumer Behavior," Journal of Consumer Research, Vol.5, March.

15. Hauser, John R. and Wernerfelt, Birger (1990), “An Evaluation Cost Model of Consideration Set,” Journal of Consumer Research, Vol. 16, March, pp. 393-408.

16. Hoffman Donna. L. and Novak, Thomas P. (1996), "Marketing in Hypermedia Computer-Mediated Environments: Conceptual Foundations," Journal of Marketing, 60, pp.50-68.

17. Hutchinson, Wesley (1986), "Discrete Attribute Models of Brand Switching," Marketing Science, 5, Fall, pp. $350-371$.

18. Hutchinson, Wesley J., Raman, Kalyan, and Mantrala K. (1994), "Finding Choice Alternatives in Memory: Probability Models of Brand Name Recall," Journal of Marketing Research, Vol. 31, November, pp. 441461.

19. Keller, K. L. (1993), “Conceptualizing, Measuring, and Managing Customer-based Brand Equity,” Journal of Marketing, Vol. 57, Issue 1. 
20. Kiely, T. (1996), "The Pleasures and Perils of Selling in Cyberspace", Insights from Marketing Science Institute, Winter/Spring 1997, Reprinted by Permission of Harvard Business Review in Briefings from Editors, September-October 1996.

21. Krishnamurthi, Lakshman and Raj, S. P. (1988), "A Model of Brand Choice and Purchase Quantity Price Sensitivities," Marketing Science, Vol. 7, No. 1, winter, 1-20.

22. Meyers-Levy, Joan (1989), "The Influence of a Brand Name's Association Set Size and Word Frequency on Brand Memory," Journal of Consumer Research, Vol.16, September, 197-207.

23. Murphy, Patrick E. and Enis, Ben M. Classifying Products Strategically. Journal of Marketing, (July 1986), 24-42.

24. Levy, Sidney J. (1978), Marketing Behavior-Its Meaning for Measurement, New York: AMACOM.

25. Lynch, John G., Jr., Marmorstein, Howard, and Weigold, Michael F. (1988), "Choice from Set Including Remembered Brands: Use of Recalled Attributed and Overall Evaluations," Journal of Consumer Research, Vol. 15, September, pp. 169-84.

26. Muthukrishnan, A. V. and Kardes, Frank R. (2001), "Persistent Preferences for Product Attributes: The Effects of the Initial Choice Context and Uninformative Experience," Journal of Consumer Research, Vol. 28, June, pp.89-104.

27. Ratchford, Brian T. (1982), "Cost-Benefit Models for Explaining Consumer Choice and Information Seeking Behavior," Management Science, 28, February, pp. 197-212.

28. Roberts, John H. and Lattin, James M. (1991), "Developing and Testing of a Model of Consideration Set Composition," Journal of Marketing Research, 28, August, pp. 281-295.

29. Scott, Jerome E. and Wright, Peter (1976), "Modeling an Organizational Buyer's Product Evaluation Strategy: Validity and Procedural Considerations," Journal of Marketing Research, Vol. 8, pp.211-24.

30. Simonson, Itamar, Huber, Joel, and Payne, John (1988), "The Relationship Between Prior Brand Knowledge and Information Acquisition Order,” Journal of Consumer Research, 14, March, pp. 566-578. 